\title{
Correction to: Brain oscillation recordings of the audience in a live concert-like setting
}

\author{
Mari Tervaniemi ${ }^{1,2}$ (1) $\cdot$ Saara Pousi ${ }^{2} \cdot$ Maaria Seppälä $^{2} \cdot$ Tommi Makkonen $^{2}$
}

Accepted: 27 January 2022 / Published online: 14 February 2022

(c) Marta Olivetti Belardinelli and Springer-Verlag GmbH Germany, part of Springer Nature 2022

Correction to: Cognitive Processing

https://doi.org/10.1007/s10339-021-01072-z

In the original publication of the article, the first and last names of the last author were interchanged and published incorrectly. The correct author name is Tommi Makkonen.

The original article has been corrected.

Publisher's Note Springer Nature remains neutral with regard to jurisdictional claims in published maps and institutional affiliations.

The original article can be found online at https://doi.org/10.1007/ s10339-021-01072-z.

Mari Tervaniemi

mari.tervaniemi@helsinki.fi

1 Cicero Learning, Faculty of Educational Sciences,

University of Helsinki, POB 9, 00014 University of Helsinki,

Finland

2 Cognitive Brain Research Unit, Department of Psychology and Logopedics, Faculty of Medicine, University of Helsinki, POB 21, 00014 University of Helsinki, Finland 